as $S 23$ with air containing concentrations of sulphur dioxide that ranged from $0 \cdot 01-0.06$ part per million gave a dry weight yield that was 45 per cent below that of plants grown in air that had been purified by passing it through a water scrubber. Some evidence was found, however, that the effect of polluted air may be masked if the rye grass is grown on soil of especially high fertility. The greenhouse experiments were supplemented by others in the field at nine different sites. These showed that plants such as rye grass, cabbages and wallflowers, in which active photosynthesis occurs during the winter months, are seriously stunted when grown in a polluted atmosphere, the reduced growth being most marked where the pollution is most concentrated. Dr. Bleasdale ended by referring to the competition for land between building and agricultural interests, and reminded his audience that the spread of suburbia combined with smoke pollution is reducing food production to an ever-increasing extent that might well become serious. Possible remedies would be to breed smoke-resistant varieties of food plants, and to apply chemicals to the plants to counteract the sulphur dioxide in the atmosphere.

These three contributions were followed by a lively general discussion in which reference was made to many aspects of the subject, including the action of a polluted atmosphere in inhibiting the development of lichens and mosses, the increasingly poor outlook for planting woodlands in the future, and the complex nature of the combined influence of soil conditions and air pollution on plant growth. Prof. H. G. Champion (University of Oxford), who has seen the damage to vegetation in the neighbourhood of the Trail smelting works in British Colunubia, said that considerable improvement had been effected there by the introduction of remedial measures at the works. From the views that were expressed it is quite evident that, apart from the damage done by soot and other solid particles emitted into the atmosphere, there is general agreement that sulphur dioxide is one of the most important causes of damage to vegetation. It must not be overlooked, however, that certain American investigators have claimed that other chemical substances, such as oxidation products of olefines, are also responsible. The discussion undoubtedly served a useful purpose in focusing attention not only on the serious damage to plant life that sometimes occurs but also on the complex of physical and chemical factors that play a part in causing this destruction. A complete solution of the problem is not likely to be quickly achieved for economic reasons; but it is to be hoped that success will come gradually through the combined endeavours of engineers, meteorologists, chemists and botanists. C. R. Metcalfe

\section{COMPARATIVE PHILOLOGY AND POLYNESIAN STUDIES}

\section{By Prof. ALAN S. C. ROSS \\ University of Birmingham}

$\mathrm{P}$ HILOLOGY (or linguistics) consists of two parts, usually called descriptive linguistics and comparative philology, respectively. The latter is technical and esoteric (therefore its nature is not easy to describe shortly), whereas the former is of a nature altogether more obvious.
The main task of descriptive linguistics is, in fact, the answering of the question: What is the best, or even, what is a good way to describe language; or, to describe a particular language ? It is very clear that the 'normal' answer to this question-namely: Languages may best be described in the terms in which Latin is conventionally described-is valueless when applied to the majority of languages. That is to say, 'Latin' grammar, with its sharp distinction between, for example, verb and noun, and its system of declension and conjugation, cannot afford us a frame for describing a language such as Tahitian, which has no trace of declension or conjugation and, apparently, has one massive part of speech corresponding to the Latin verb, noun, adjective and adverb taken together.

Some philologists consider that no satisfactory answer to the question: How may a language be described? has yet been given. Others, however, think that they have given an answer and have established, in several schools already somewhat at war with each other, the subject known as structural linguistics. The main centres of this new subject are, first, many American universities, and then the Universities of London, Paris and Copenhagen.

The second branch of linguistics, comparative philology, makes statements of which the following are the three main types: (1) 'English and German are related languages'; (2) 'the English word stone is philologically identical with the German word stein'; (3) 'an Anglo-Saxon long $\bar{a}$ becomes a Modern English long $\tilde{o}$ (as in AS. st $\bar{x} n$ MnE. stone'). Statements of all these types are technical and entirely non-obvious; the learner of comparative philology must be prepared to expend a good deal of hard work before he can expect to understand them.

The 'axiom' underlying statements of the first kind is simple to state; it is merely that 'Two languages are defined as related if, and only if, they were once one language'. Thus French and Spanish are related because, and only because, they were both once Latin. Developing this axiom in an obvious manner, it is easy to establish the concept 'Family of Languages' ; for example, English, German, Dutch, etc., form the Germanic family of languages.

Comparative philology, in its modern sense, came into being at the beginning of the nineteenth century. One of its main tasks has been the arranging of the languages of the world into families of related languages, and great progress has been made in this field. To-day, the thousands of languages in the world stand arranged into hundreds of different families (with no relationship proved to subsist between any pair of the families). The next-and incomparably the more laborious-task is the production of all possible statements of the second and third types for each family. Only when this has been done can the comparative philology of a family be said to exist.

Even in pre-1914 Germany (where the subject flourished most), the number of comparative philologists has always been small, in comparison with the number of, for example, natural seientists. It is therefore scarcely surprising that, in the century and a half which has elapsed, it has not been possible to bring into being (still less to complete) the comparative philology of more than seven families, namely : (1) Indo-european (to which, for example, English, Latin and Russian belong) ; (2) Uralian (for example, Finnish, Hungarian and Samoyede); (3) Semitic (for example, Hebrew and Arabic); 
Turkish-Mongol- $r$ Tungus (sufficiently described by its name) ; (5) Bantu (for example, Zulu) ; (6) Dravidian (for example, Tamil); (7) Indonesian (for example, Malay).

The establishment of the comparative philology of the remaining families of the world may well take many centuries of research work, and the prospect has recently been darkened by the almost complete gulf which now separates the new and fashionable structural linguistics from the old-established comparative philology - a gulf which, in extreme cases, may extend to an actual despising by the structuralist of the rigid disciplines of comparative philology.

Comparative philology is of immense value and importance to other subjects, for, it must be remembered, it is unsafe to make even the simplest statement involving the history of a word (such as, that it is a borrowing from another language, or, that earlier it had a different meaning) without reference to a specialist in the relevant comparative philology. Such statements are, alas, often made without such reference and they are, naturally, always without value. Although comparative philology is so esoteric, its results are often much appreciated by nonphilologists ; to take two examples, common enough in Britain, the classical scholar uses such results with profit for Homeric criticism, and the results of English place-name study are of great value to the historian -though both are usually entirely ignorant of even the nature of comparative philology.

As already stated, the outlook for the establishment of a comparative philology for families of languages still without it is rather poor. There is, however, one exception to this statement and the purpose of the present article is to direct attention to it. There is, in fact, one family the comparative philology of which, at the moment untouched, could be established by a very small group of scholars in half a life-time's work. This family is Polynesian.

The reason why it is precisely Polynesian that, of all the 'untouched' families of the world, is in so exceptionally favourable a position, is that Polynesian is closely related to Indonesian, a family the comparative philology of which is in an extremely advanced state, by reason of the labours of generations of Dutch scholars. Furthermore, the Polynesian languages are few in number (Maori, Tongan, Hawaiian, Samoan and Tahitian are the principal ones), the relationship between them is very close (Hawaiian and Tahitian are scarcely more 'distant' than are German and Dutch), and, finally, their relationship to the Indonesian languages is also fairly close, being of somewhat the same order as is the relationship between Lithuanian and Russian. The Balto-Slavonic family consists of two branchesSlavonic (with, for example, Russian, Czech and Bulgarian) and Baltic (comprising Lithuanian, Lettish and Old Prussian); if we were to imagine that the comparative philology of Slavonic had been thoroughly worked out but that that of Baltic was still untouched (which is, of course, not the actual case), then this hypothetical state of work to be done would give us a very fair picture of the actual state existing in regard to Indonesian (worked out) and Polynesian (untouched).

It seems, then, desirable that a comparative philology of Polynesian should be inaugurated forthwith. How may this task best be accomplished?

Polynesian falls naturally under the head of 'Pacific Languages'-which term I here use to com- prise (1) the Polynesian family ; (2) the Melanesian family; (3) the very many different families of New Guinea; (4) the many different families of Australia. To-day, the study of Pacific languages is everywhere linked with either anthropology or structural linguistics. Neither of these linkings is likely to be of much value to the proposed com. parative philology of Polynesian. It would not be desirable to attempt to turn either an anthropologist or a structuralist into a comparative philologist; anthropologists rather naturally tend to regard linguistics as a subordinate subject and $I$ have indicated the attitude of the structuralists above. Furthermore, neither an anthropologist nor a structuralist is likely to have received any grounding in the disciplines of comparative philology. It seems, then, that the proposed comparative philology of Polynesian had better be essentially independent of both the subjects mentioned (though it might well have liaison with and, later, offer help to both anthropologists and structuralists).

The proposed study must, of course, be centred in some university or institute and not more than six choices present themselves.

(1) In London the School of Oriental and African Studies, which has recently had so many new linguistic developments (for example, as concerns Africa and South-East Asia), has shown a slight interest in Pacific languages. But this interest has been purely descriptive, indeed structuralist. Comparative philologists may regret that the languages in the Pacific field selected for study by the School have been mostly Melanesian (for example, Gilbertese), a family which offers no hope of the establishment of a comparative philology for many lifetimes, instead of Polynesian, which offers a real and present hope of such establishment. But it may be that, from the point of view of the structuralist, the Melanesian languages are more interesting.

(2) After a terrible record of neglect, first of its own aboriginal languages, then, even less excusably, of New Guinea languages from the end of the penultimate war onwards, Australian university life has at last begun to take a modest interest in these languages. Rather naturally, the study seems to be at least slightly subordinate to anthropology; but this is not the main difficulty, which is simply the enormous number of different languages requiring study. Australian philologists will surely be occupied for many decades with the plain task of describing them.

(3) At Honolulu there is a long-established tradition of Polynesian studies at the Bernice P. Bishop Museum. However, this interest is, in the main, anthropological and, furthermore, the supreme dominance of structuralism in the United States would be likely to militate against the establishment of any new comparative philology.

(4) In Paris two Pacific languages are admittedly taught at the Ecole des langues orientales vivantes; these are Wailu (the major language of New Caledonia, a Melanesian language) and Tahitian (a Polynesian language). The instruction and interest here are, however, confined to the imparting of a practical knowledge of these languages to French people going to these areas, and there is no sign of any interest in comparative Polynesian philology, or even in any other Polynesian language.

None of the first four choices, neither London, Honolulu, Paris nor an Australian university, thus seems in any way especially suitable as a venue for 
the proposed study of comparative Polynesian philology. The remaining two choices deserve, however, much more serious consideration.

(5) In Holland the comparative philology of Indonesian has a long and dignified tradition (the literature is, naturally, almost entirely in Dutch) and it is on Indonesian that the proposed comparative philology of Polynesian is, of course, to be based. At first sight, then, some Dutch university would seem particularly suitable for the establishment of such a study. But two points could be urged against this choice. First, Governments are not usually prepared to devote money to the languages of areas in which they have no territorial interest, and Holland has none in Polynesia. Second, who can forecast what deleterious effect the present rift between Indonesia and Holland may not have upon these studies hitherto flourishing in Holland ?

(6) There remains only New Zealand. Here there has for long been an interest in Maori studies. At the moment this interest is oriented entirely in the direction of either anthropology or (by reason of American interest) of structural linguistics. But there seems no reason why an equal, or surpassing, interest in comparative Polynesian philology could not be built up. New Zealand has always been eminent in what is essentially a branch of comparative philology, in that, for its size, it has produced a quite undue proportion of scholars distinguished in Anglo-Saxon and Middle English (though it has, admittedly, exported most of them to Britain). New Zealand has another advantage: only here, in the whole of Polynesia, is there, at the moment, any likelihood of there existing a native speaker of a Polynesian language (namely, Maori) with sufficient preliminary education for it to be possible to turn him into a comparative Polynesian philologist.

It seems, indeed, that one of the New Zealand universities would be the ideal venue for the settingup of the unit, which, it is proposed, will establish the comparative philology of Polynesian. The practical details of such a setting-up remain for consideration.

In the first place, it may be pointed out that the unit could well be a small one. A professor, two lecturers and a secretary could probably accomplish the whole task in a decade. By modern university financial standards, the expenditure for such a unit would not be all too great. But funds for three ancillary purposes would have to be provided.

(1) Library. Philology, much more than medicine and natural science, requires old books as well as new; nowadays, it is not possible to obtain the out-of-print books of any philology by second-hand purchase and, in the main, copies must be obtained by photographic aids (photostats, 'Copycats', microfilms, etc.). But, from the financial point of view, Polynesian is, in this respect, very fortunately placed, for its literature is, comparatively, very scanty. An initial expenditure of $£ 1,000$, plus an annual grant of $£ 100$, would probably be sufficient for the acquiring of a substantial Polynesian collection (the comparable figures for a Balto-Slavonic collection might well be $£ 15,000$ and $£ 500$ ).

(2) Travelling. The smallness of the library expenditure would, however, be more than offset by the high travelling expenses. Since Polynesian languages can only be learnt by speaking, it would clearly be desirable for members of the proposed unit to spend much time travelling in the Pacific. Further- more, they would have to visit the Indonesianists in Holland from time to time (and on these European visits they would, of course, also have to keep in touch with other philologists in Europe).

(3) Publication. Naturally, the results of the establishment of the comparative philology of Polynesian would, in due course, have to be published. Probably a series of monographs, in conjunction with a periodical, would best meet the case here. Here perhaps it would be desirable to envisage the nature of the publications required. An adequate descriptive and comparative apparatus for an Indo-european language (and we must accept the same standard for Polynesian also) might consist of : (a) descriptive 'grammar' (declension, conjugation-in application to different parts of speech) and 'syntax' (uses of the same, word-order, etc.) ; (b) the complete catalogue of all things such as (for Modern English) 'AngloSaxon $\bar{a}$ becomes Modern English ō (AS. stān MnE. stone)', mentioned above, and the historical raison d'être of all that is set out under $(a)$ above; (c) a dictionary into the same, or some other language (in the latter case, with inverse dictionary also); $(d)$ an etymological dictionary (that is, for English, the setting-out of all possible equations of Type English stone = German stein, mentioned above).

Thus, A. Heusler, "Altisländisches Elementarbuch" might serve as a (small-scale) model for $(a)$ and $(b)$ combined (in respect of Old Icelandic), the "New (or Oxford) English Dictionary" as a model for (c) and (d) combined (in respect of English).

In addition to the 'advanced' apparatus $(a),(b)$. (c) and $(d)$, there should be an 'elementary' apparatus also-something to help the beginner on his way to more serious methods of study (such as speaking); the standard Gaspey-Otto-Sauer grammars might serve as examples of this.

Owing to the nature of Polynesian languages (no declension or conjugation, virtually no parts of speech), there would be great difficulty in writing descriptive grammars of Type $a$ (above). As already mentioned, it is not practicable for them to be written on the 'Latin' method-as can readily be observed from those already written. It may be doubted, too, whether the structuralists are in fact going to give practical help here. There seem to be only two possible solutions to the difficulty. First, to model the grammar on that of ancient Indonesian, by now well elaborated by the Dutch philologists, that is, to regard the phenomena of, for example, Tahitian as decay-products of those of Old Javanese ; second, to write no grammars at all, but to relegate all that would be in them to the dictionaries. A study of the world's great dictionaries-for example, "New English Dictionary" (note, for example, the head-words So adv. and Set vb.), H. G. Liddell and R. Scott, "GreekEnglish Lexicon", J. and W. Grimm, "Deutsches Wörterbuch", "Groote woordenboek der nederlandsche taal", and "Svenska Akademiens ordbok"-will undoubtedly convince the reader that this method is practicable. The proposed 'Primers' would, on this second method, merely consist of text, literal translation and glossary modelled on the dictionary.

If this second method were adopted (and it is, I feel, the better one) the problem of publication becomes greatly simplified and is reduced to the following scheme.

(I) For each Polynesian language separately: (1) a dictionary, into English, modelled on the "New English Dictionary" and with inverse index ; (2) a primer. 
(II) For the aggregate of Polynesian languages, taken together : (1) a comparative phonology, that is, something setting out all results of the Type AS. stān : MnE. stone (mentioned above); W. Streitberg, "Urgermanische Grammatik", might serve as a model ; (2) an etymological dictionary; A. Walde and J. Pokorny, "Vergleichendes Wörterbuch der Indogermanischen Sprachen", might serve as a model.

There is, finally, the question of selecting and training the proposed unit for the establishment of the comparative philology of Polynesian. All its members must, of course, be thoroughly conversant with comparative philology, and this end is probably best attained by their having passed through some quite conventional school of philology (such as 'English Language', 'French Language' or Sanskrit, as taught in Great Britain). Next they must have an adequate training in Indonesian, and this can only be gained by at least three years residence in Holland (and, possibly, some time in Indonesia). It is much to be hoped that at least one member of the unit will be a native speaker of Maori (one who had gone through an 'English Language' training in a New Zealand university would be ideal) ; it might well be desirable to invite a distinguished Dutch Indonesianist to spend at least some time as another member.

\section{CHEMICAL RESEARCH LABORATORY, TEDDINGTON REPORT FOR 1952}

\footnotetext{
T
}

HE report of the Chemistry Research Board, signed by the chairman, Prof. E. L. Hirst, and the report of the director of the Chemical Research Laboratory, Teddington, Dr. D. D. Pratt, make up the contents of "Chemistry Research 1952", which has recently been published*. To these reports are appended a list of more than fifty papers submitted for publication during the year, and lists of the staff of the Laboratory, of metals held by the Pure Metals Committee, of standard substances available and of species in the National Collection of Industrial Bacteria. Both reports refer to the improvement in working conditions through the occupation of the new Radiochemical Building in May and of the Microbiological Buildings in November, thus easing the overcrowded conditions in the main building and enabling the construction of a mass spectrometer and research on high-temperature corrosion of metals by hot flue gases and by boiler-water to be commenced. Nevertheless, the Board records the opinion that the scientific staff is still too small in relation to the programme, though it merely expresses the hope that additional staff will be provided "when circum. stances permit".

The Board's report again stresses the value of the work of the Corrosion of Metals Group. The value of the electrical capacitance method of measuring the rate of water uptake of a paint film on immersed metal has been further investigated with anticorrosive paints and an anti-fouling paint, and an apparatus has been constructed in which specimens can be subjected to controlled amounts of spray solutions, infra-red and ultra-violet radiations. Studies of the mechanism of corrosion inhibition by * Department of Scientific and Industrial Research. Report of the Chemistry Research Board, with the Rcport of the Director of the plates. (Iondon: H.M.S.O., 1953.) 4s. 6d. net. potassium chromate and sodium benzoate using radioactive tracer techniques indicate that the former is more firmly held by the metallic surface. Bacteriological examination of a clay soil in which the expected attack on buried pipes had not occurred revealed the presence of a species of Actinomyces toxic to sulphate-reducing bacteria. Examination of a waterlogged clay soil from a site at Hungate, York, in which ancient buried iron particles were excellently preserved in spite of the presence of sulphate-reducing bacteria, anaerobic conditions and the appropriate $p \mathrm{H}$ range for bacterial activity, showed that the activity of the bacteria was suppressed by concentrations of tannin of 0.01 per cent and upwards. In conjunction with the British Iron and Steel Research Association, an inquiry has been initiated into the incidence of buried water-pipe failure in Britain and the efficacy of cathodic protection. Other investigations have included a study of the effect of pressure on the rate of oxidation of copper at $100-250^{\circ} \mathrm{C}$. and the use of film-stripping and microchemical techniques in a study of the influence of surface condition on the low-temperature oxidation of mild steel, while an investigation of the effect of small amounts of salts and particles left on metal surfaces subject to different treatments in metal-finishing processes has shown that blistering of paint on sheet-steel articles may be caused by salt contamination of metal surfaces arising in treatments prior to painting. The importance of humidity in the corrosion of steel has been confirmed in tests carried out in collaboration with the Institute of Petroleum Protective Panel, and good protective value has been obtained by temporary protective coatings in which corrosion inhibitors are incorporated in thixotropic suspensions of inorganic earths : although soft and easily removed when no longer required, these coatings do not flow from the protected surfaces on storage.

The Inorganic Group has completed its work on the elimination of arsenical impurities from germanium; further work has been carried out on the production of dicalcium phosphate from phosphate rock by the action of nitric acid followed by ammoniation, and studies of the action of sulphuric acid on an apatite from Uganda indicate that the apatite can be fairly readily converted to phosphoric acid provided the concentration of the sulphuric acid is carefully controlled. The study of the reaction between ferric oxide and ammonium sulphate has been continued; a search was commenced for possible sources of selenium from waste materials, and spectrochemical methods for detecting and estimating this element were being sought, as well as methods for determining phosphorus in organic compounds which can be applied to the determination of this element in ionexchange resins. In collaboration with the Radiochemical Group, the carrier technique, used for the micro-estimation of thorium, has been adapted to the direct determination of tantalum and niobium separately in ores. The chromatographic process for the separation of these metals that has been worked out by the Radiochemical Group has proved simple and accurate for a wide variety of products, while the quantitative separation of palladium, platinum, rhodium and iridium by a chromatographic process has been practically completed, and preliminary experiments have shown that bis. muth can be separated chromatographically from a solution containing nitric acid. Extension of the work on the adsorption and elution of complex cyanides of gold, copper and iron with 'Amberlite 